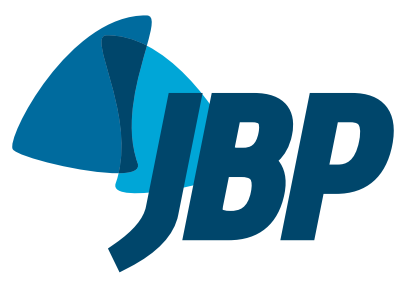

\title{
Diaphragmatic mobility: relationship with lung function, respiratory muscle strength, dyspnea, and physical activity in daily life in patients with COPD
}

Flávia Roberta Rocha ${ }^{1}$, Ana Karla Vieira Brüggemann ${ }^{1}$, Davi de Souza Francisco ${ }^{1}$ Caroline Semprebom de Medeiros ${ }^{1}$, Danielle Rosal ${ }^{2}$, Elaine Paulin ${ }^{1}$

1. Curso de Fisioterapia, Universidade do Estado de Santa Catarina - UDESC Florianópolis (SC) Brasil.

2. Fundação Universidade Regional de Blumenau - FURB - Blumenau (SC) Brasil.

Submitted: 22 March 2016.

Accepted: 31 October 2016

Study carried out at the Universidade do Estado de Santa Catarina - UDESC

-Florianópolis (SC) Brasil.

\begin{abstract}
Objective: To evaluate diaphragmatic mobility in relation to lung function, respiratory muscle strength, dyspnea, and physical activity in daily life (PADL) in patients with COPD. Methods: We included 25 patients with COPD, classified according to the Global Initiative for Chronic Obstructive Lung Disease criteria, and 25 healthy individuals. For all of the participants, the following were evaluated: anthropometric variables, spirometric parameters, respiratory muscle strength, diaphragmatic mobility (by $X$-ray), PADL, and the perception of dyspnea. Results: In the COPD group, diaphragmatic mobility was found to correlate with lung function variables, inspiratory muscle strength, and the perception of dyspnea, whereas it did not correlate with expiratory muscle strength or PADL. Conclusions: In patients with COPD, diaphragmatic mobility seems to be associated with airway obstruction and lung hyperinflation, as well as with ventilatory capacity and the perception of dyspnea, although not with PADL.

Keywords: Pulmonary disease, chronic obstructive; Diaphragm; Spirometry; Dyspnea; Maximal respiratory pressures.
\end{abstract}

\section{INTRODUCTION}

Several studies have shown a decrease in diaphragmatic mobility (DM) in patients with COPD. ${ }^{(1-4)}$ However, COPD also has significant extrapulmonary effects, ${ }^{(5)}$ which result in systemic inflammation, loss of muscle mass, ${ }^{(6,7)}$ malnutrition, depression, ${ }^{(8)}$ physical deconditioning, ${ }^{(9)}$ and, consequently, reduced health status. ${ }^{(10)}$

Despite significant systemic involvement in patients with COPD, few studies have investigated the relationship between DM and the systemic changes caused by COPD. However, the relationship of DM with the six-minute walk distance, ${ }^{(2,11)}$ dyspnea, ${ }^{(2)}$ and mortality ${ }^{(12)}$ has previously been described.

Several studies have shown a relationship between DM and lung function changes. ${ }^{(3,11,13)}$ Recently, Davachi et al. ${ }^{(11)}$ found that DM was greater in patients classified as having mild COPD than in those classified as having very severe COPD. They also found that DM was related to FVC and slow VC (SVC). It has previously been shown that DM is associated with air trapping, ${ }^{(3,14,15)}$ maximal voluntary ventilation (MVV) ${ }^{(3)}$ and lung hyperinflation. ${ }^{(1)}$ These results support the hypothesis that decreased DM is related to lung disease severity.

To date, no studies have investigated the relationship between DM and physical activity in daily life (PADL), and few have related DM to dyspnea and lung function. ${ }^{(2,3)}$ Therefore, the primary objective of the present study was to evaluate DM in relation to lung function, dyspnea, and PADL in patients with COPD. A secondary objective was to compare COPD patients and healthy individuals in terms of lung function, respiratory muscle strength, and DM.

\section{METHODS}

This was a quantitative descriptive cross-sectional study. It was approved by the local human research ethics committee (Protocol no. CAEE 08871312.7.0000.0118). All participants gave written informed consent. The study sample consisted of 25 patients with COPD (14 males and 11 females) and 25 healthy individuals (5 males and 20 females). We included patients diagnosed with COPD in accordance with the 2015 Global Initiative for Chronic Obstructive Lung Disease criteria $^{(9)}$ and meeting the following criteria: 1 ) having no associated pulmonary, cardiovascular, or musculoskeletal diseases; 2) having participated in no training programs in the 6 months prior to the study; 3) requiring no oxygen therapy supplementation; and 4) being a nonsmoker. The criteria for inclusion of healthy individuals in the present study were as follows: 1) having normal pulmonary function test results $\left(\mathrm{FEV}_{1} /\right.$ FVC $\geq 0.7 ; \mathrm{FEV}_{1} \geq 80 \%$ of predicted; and FVC $\geq 80 \%$ of predicted); 2) being a nonsmoker; and 3) having no cardiorespiratory, hepatic, neurological, or oncologic diseases. The exclusion criteria were as follows: 1) being unable to perform any of the required tests (being unable to understand the instructions or being uncooperative);

Correspondence to:

Ana Karla Vieira Brüggemann. Laboratório de Fisioterapia Respiratória, Centro de Ciências da Saúde e do Esporte, Universidade do Estado de Santa Catarina - CEFID/

UDESC - Rua Pascoal Simone, 358, Coqueiros, CEP 88080-350, Florianópolis, SC, Brasil.

Tel.: 5548 3664-8602 or 5548 9665-8289. E-mail: anakarla_vb@hotmail.com

Financial support: None. 
2) experiencing COPD exacerbation during the study period; 3) having cardiorespiratory or musculoskeletal complications during the tests; and 4) having a body mass index $(B M I)>30 \mathrm{~kg} / \mathrm{m}^{2}$ (i.e., being obese).

\section{Spirometry and respiratory muscle strength}

Spirometry was performed with a previously calibrated portable digital spirometer (EasyOne ${ }^{\circledR}$; ndd Medical Technologies, Andover, MA, USA), in accordance with the methods and criteria recommended by the American Thoracic Society and the European Respiratory Society. ${ }^{(16)}$ The following parameters were measured: FVC; FEV $_{1}$; FEV FVV $_{1}$ before and 15 min after inhalation of a bronchodilator (albuterol, $400 \mu \mathrm{g})$; and inspiratory capacity (IC). A minimum of three acceptable maneuvers and two reproducible maneuvers were performed; for IC, however, the average of three maneuvers was used, as reported by Miller et al. ${ }^{(16)}$ All spirometric variables are expressed as absolute values and as a percentage of reference values, in accordance with Pereira et al. ${ }^{(17)}$

A digital manometer (MVD500 ${ }^{\circledR}$; Globalmed, Porto Alegre, Brazil) attached to a mouthpiece with an air outlet of $1 \mathrm{~mm}$ in diameter was used in order to measure inspiratory and expiratory muscle strength. MIP and MEP were measured as indicators of inspiratory and expiratory muscle strength, respectively, in accordance with the Brazilian Thoracic Association guidelines. ${ }^{(18)}$ MIP was measured after a maximal expiratory maneuver (near RV), whereas MEP was measured after a maximal inspiratory maneuver (near TLC). A minimum of three acceptable maneuvers and two reproducible maneuvers were performed. The values of MIP and MEP are expressed as absolute values and as a percentage of reference values, in accordance with Neder et al. ${ }^{(19)}$ The average of the reproducible maneuvers was used in the present study.

\section{$D M$}

Patients initially underwent familiarization with diaphragmatic breathing for diaphragmatic proprioception and maximal evaluation of diaphragm amplitude during radiographic examination. Patients were asked to perform two series of ten repetitions of diaphragmatic breathing, proprioceptive stimulation being provided by placing their hands on their chest and abdomen and verbal encouragement being provided in order to enable patients to direct the air toward the lung bases, in accordance with Leal.(20)

After having become familiar with diaphragmatic breathing, patients performed three SVC maneuvers using a Wright spirometer (Ferraris Medical Ltd., Hertford, England). SVC maneuvers were performed from TLC to RV and from RV to TLC. The highest value was recorded for comparison with the value obtained during the evaluation of DM, in order to determine whether patient respiratory effort was the same before and during DM evaluation.

After having become familiar with the diaphragm and having performed all SVC maneuvers, patients underwent DM evaluation by anteroposterior chest X-rays, which were taken with patients lying supine on a fluoroscopy table. A radiopaque ruler was placed longitudinally under the trunk in the craniocaudal direction, near the thoracoabdominal junction, for subsequent correction of the magnification caused by the divergence of the X-rays. The same film was used for all examinations, which were performed during a maximal inspiratory maneuver and a maximal expiratory maneuver.

DM was measured by the method of Saltiel et al.(21): a straight line was drawn from the highest point of the hemidiaphragm during exhalation to the hemidiaphragm during inhalation with the use of a $150-\mathrm{mm}$ digital caliper (Messen; Sensor Technology Co., Guangdong, China; Figure 1).

\section{Dyspnea}

Dyspnea was measured with the modified Medical Research Council dyspnea scale,(22) the degree of dyspnea ranging from 0 (no dyspnea) to 4 (very severe dyspnea). Patients were instructed to select the number that best represented their perception of dyspnea.

\section{PADL}

PADL was evaluated with a triaxial accelerometer (DynaPort activity monitor; McRoberts, The Hague, the Netherlands), which is a small, lightweight device worn on a belt around the waist. It can distinguish among activities such as sitting, reclining, and walking, and it measures the time spent in each activity. ${ }^{(23)}$ Patients were monitored $12 \mathrm{~h}$ per day for two consecutive days, patient monitoring beginning immediately after waking. Patients were subsequently classified as active (on the basis of the time spent walking) or sedentary (on the basis of the time spent sitting or lying down), the average of the two days being used for analysis. Patients were instructed on how to position the device and received a manual with clear instructions and explanatory illustrations. In addition, they were asked not to change their daily activities while wearing the device.

\section{Sample size calculation}

The power of the sample, which consisted of 25 patients, was calculated post hoc with the free statistical software program G*Power, version 3.1.9.2.

\section{Statistics}

All statistical analyses were performed with the IBM SPSS Statistics software package, version 20.0 (IBM Corporation, Armonk, NY, USA), descriptive (mean and standard deviation) and inferential statistics being used. Data normality was verified with the Shapiro-Wilk test. Either a parametric test or a nonparametric test was used depending on the data distribution. The independent sample t-test and the Mann-Whitney $U$ test were used in order to determine the difference between the two groups. In order to evaluate the correlation of DM with

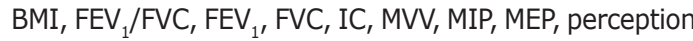


of dyspnea, and PADL, Pearson's and Spearman's correlation coefficients were used for parametric and nonparametric variables, respectively. The magnitude of the correlations was described in accordance with Dancey and Reidy, ${ }^{(24)}$ values of $r=0.10-0.39$ indicating a weak correlation, value of $r=0.40-0.69$ indicating a moderate correlation, and values of $r=0.70-1.00$ indicating a strong correlation. The level of significance was set at $5 \%(p<0.05)$ for all tests.

\section{RESULTS}

A total of 25 COPD patients and 25 healthy individuals who did not differ in terms of age, weight, or respiratory muscle strength participated in the present study. Although the individuals in the control group were classified as being overweight and those in the COPD group were classified as being normal weight, ${ }^{(25)}$ there was no statistically significant difference between the two groups regarding the BMI. There were differences between the two groups regarding height, $\mathrm{FEV}_{1} / \mathrm{FVC}$,
$\mathrm{FEV}_{1}, \mathrm{FVC}$, and DM. The results for the two groups are presented in Table 1.

The coefficients of determination for DM and the study variables in the COPD group are presented in Table 2. For a significance level of $5 \%$, the following powers were found: 0.96 for $\mathrm{FEV}_{1} / \mathrm{FVC} ; 0.95$ for $\mathrm{FEV}_{1}$; 0.84 for FVC; 0.99 for IC; 0.99 for MVV; 0.95 for MIP; and 0.73 for the perception of dyspnea. Given that neither MEP nor PADL correlated with DM, neither variable was used.

In the COPD group, DM correlated moderately with lung function, inspiratory muscle strength, and the perception of dyspnea. In addition, it correlated strongly with MVV and IC. In the control group, DM did not correlate with any of the lung function or respiratory muscle strength variables (Table 2).

\section{DISCUSSION}

In the present study, DM was found to correlate moderately with $\mathrm{FEV}_{1}$ and strongly with IC in COPD
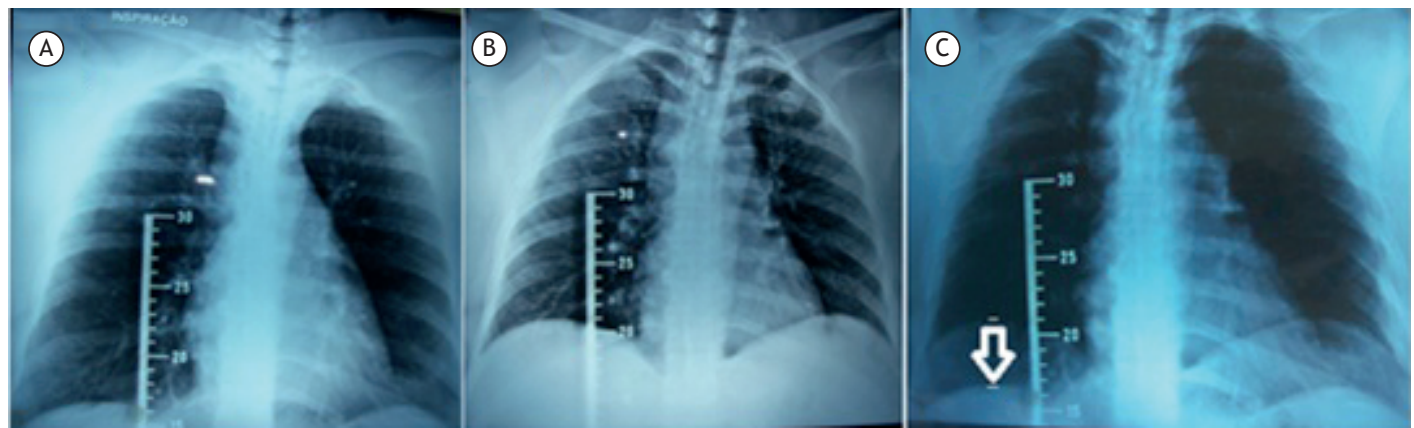

Figure 1. Anteroposterior chest X-rays. In A, chest X-ray taken during a maximal expiratory maneuver; in $\mathrm{B}$, chest $X$-ray taken during a maximal inspiratory maneuver; and in C, superimposition of the two aforementioned images, the image of the radiographic ruler being used as reference to assess diaphragmatic mobility.

Table 1. Anthropometric, spirometric, and functional characteristics of the groups studied.

\begin{tabular}{|c|c|c|c|}
\hline Variable & Control & COPD & $\mathbf{p}$ \\
\hline Age, years & $64.68 \pm 6.63$ & $67.56 \pm 9.21$ & 0.21 \\
\hline Height, m & $1.59 \pm 0.11$ & $1.66 \pm 0.08$ & 0.01 \\
\hline Weight, kg & $64.86 \pm 9.85$ & $68.38 \pm 11.58$ & 0.25 \\
\hline $\mathrm{BMI}, \mathrm{kg} / \mathrm{m}^{2}$ & $25.13 \pm 2.81$ & $24.64 \pm 3.08$ & 0.52 \\
\hline $\mathrm{FEV}_{1} / \mathrm{FVC}$ & $0.79 \pm 0.06$ & $0.54 \pm 0.12$ & 0.001 \\
\hline FVC, \% predicted & $99.96 \pm 13.95$ & $71.84 \pm 17.08$ & 0.001 \\
\hline $\mathrm{FEV}_{1}, \%$ predicted & $98.20 \pm 12.39$ & $53.88 \pm 21.62$ & 0.001 \\
\hline IC, $\mathrm{L}$ & - & $2.16 \pm 0.76$ & - \\
\hline IC, \% predicted & - & $91.32 \pm 64.15$ & - \\
\hline $\mathrm{MVV}, \mathrm{L} / \mathrm{min}$ & - & $52.84 \pm 26.40$ & - \\
\hline MIP, $\mathrm{cmH}_{2} \mathrm{O}$ & $73.25 \pm 18.66$ & $62.88 \pm 19.05$ & 0.058 \\
\hline MEP, $\mathrm{cmH}_{2} \mathrm{O}$ & $96.48 \pm 37.55$ & $99.40 \pm 24.60$ & 0.74 \\
\hline mMRC scale score & & $1.24 \pm 0.77$ & - \\
\hline $\mathrm{DM}, \mathrm{mm}$ & $62.82 \pm 14.86$ & $41.73 \pm 19.39$ & 0.001 \\
\hline Active time, $\min$ & - & $228.12 \pm 105.80$ & - \\
\hline Number of steps & - & $6388.12 \pm 3671.66$ & - \\
\hline Movement intensity, $\mathrm{m} / \mathrm{s}^{2}$ & - & $0.18 \pm 0.03$ & - \\
\hline Sedentary time, $\min$ & - & $500.12 \pm 128.76$ & - \\
\hline
\end{tabular}

BMI: body mass index; IC: inspiratory capacity; MVV: maximal voluntary ventilation; mMRC: modified Medical Research Council; and DM: diaphragmatic mobility. 
patients, which is possibly due to the fact that increased airflow obstruction, as assessed by $\mathrm{FEV}_{1}$, and static lung hyperinflation, as assessed by IC, increase the workloads that affect the chest wall, placing the diaphragm at a geometric and mechanical disadvantage.(26,27) In addition, lung hyperinflation reduces the ability of the diaphragm to generate flow and pressure, ${ }^{(28)}$ resulting in decreased diaphragmatic excursion. ${ }^{(29)}$

Lung hyperinflation is one of the primary changes in patients with COPD; however, air trapping is the principal factor limiting DM in such patients. ${ }^{(3)}$ Structural changes result in diaphragm remodeling, which results in flattening of the diaphragm and, consequently, decreased diaphragmatic excursion. ${ }^{(30)}$ The aforementioned changes explain the differences in DM and lung function between COPD patients and healthy individuals; they were expected and have previously been reported. ${ }^{(1-3,29)}$

In the present study, a strong correlation was found between DM and MVV in patients with COPD, showing that a greater DM translates to a better ventilatory capacity. This finding is in agreement with those of Kang et al., ${ }^{(31)}$ who found a significant correlation between DM and MVV and posited that there might be a relationship between decreased DM and hypercapnia in patients with COPD.

In patients with COPD, airflow limitation during exercise is due to reduced ventilatory capacity associated with increased pulmonary obstruction and, consequently, lung hyperinflation, as evidenced by reduced IC and ventilatory reserve. ${ }^{(32)}$ In the present study, in which patients with moderate to severe obstruction participated, DM correlated moderately with IC, which also accounted for $65 \%$ of the variation in DM, reinforcing the influence of lung hyperinflation on diaphragmatic mechanics. However, it is known that the influence of air trapping on DM can be greater than that of lung hyperinflation itself. ${ }^{(3)}$

Although DM has been shown to correlate with parameters such as pulmonary obstruction, lung hyperinflation,(33) and air trapping, (3) Davachi et al. (11) found no relationship between DM and lung hyperinflation, which is possibly due to the fact that they selected patients with less severe COPD and, consequently, reduced airflow obstruction, resulting in less damage to the diaphragm.

In the present study, a moderate negative correlation was found between DM and the perception of dyspnea in patients with COPD, indicating that changes in the position of the diaphragm make ventilation difficult, reducing respiratory capacity and increasing the sensation of dyspnea. ${ }^{(34)}$ These findings corroborate those of Paulin et al., (2) who found that patients with decreased DM had a greater sensation of dyspnea after submaximal exercise.

Although no correlation was found between PADL and DM in the COPD patients in the present study, it is known that exercise capacity decreases with the progression of the disease. ${ }^{(35)}$ This creates a vicious cycle of increasing dyspnea during physical activity, leading to physical inactivity, decreased physical conditioning, and an increased number of comorbidities and hospitalizations. ${ }^{(36)}$ It has been shown that, in comparison with healthy, sedentary elderly individuals, most COPD patients spend more time sitting or lying down than walking or standing ${ }^{(23,37)}$; however, to date, no studies have established a relationship between DM and PADL in COPD patients.

It is of note that assessment of PADL by means of a triaxial accelerometer reveals how much individuals are physically active or inactive in their daily life. ${ }^{(38)}$ However, assessment of PADL with a triaxial accelerometer probably depends on several factors other than DM evaluation, and this might explain the lack of correlation between these variables. In addition, it is possible that the number of patients in the study sample and the evaluation period were insufficient to observe this relationship.

In the present study, no relationship was found between DM and the BMI. Kantarci et al. (39) performed a multiple regression analysis and found that waist circumference apparently plays a more significant role

Table 2. Relationship between diaphragmatic mobility and the study variables in the COPD group.

\begin{tabular}{lccc}
\multicolumn{1}{c}{ Variable } & $\mathbf{p}$ & $\mathbf{r}$ & $\mathbf{r}^{2}, \%$ \\
$\mathrm{BMI}, \mathrm{kg} / \mathrm{m}^{2}$ & 0.20 & 0.58 & 20 \\
$\mathrm{FVC}, \%$ predicted & 0.01 & 0.48 & 23 \\
$\mathrm{FEV}_{1}, \%$ predicted & 0.003 & 0.56 & 32 \\
$\mathrm{FEV}_{1} / \mathrm{FVC}$ & 0.002 & 0.58 & 34 \\
$\mathrm{IC}, \mathrm{L}$ & 0.001 & 0.80 & 65 \\
$\mathrm{MVV}, \mathrm{L} / \mathrm{min}$ & 0.001 & 0.73 & 54 \\
$\mathrm{MIP}, \mathrm{CmH}_{2} \mathrm{O}$ & 0.003 & 0.56 & 32 \\
$\mathrm{MEP}, \mathrm{CmH}_{2} \mathrm{O}$ & 0.10 & 0.33 & 11 \\
$\mathrm{mMRC}$ scale score & 0.01 & -0.48 & 18 \\
Active time, min & 0.82 & -0.04 & 0.2 \\
Number of steps & 0.85 & -0.04 & 0.2 \\
Movement intensity, $\mathrm{m} / \mathrm{s}^{2}$ & 0.26 & 0.23 & 5 \\
Sedentary time, min & 0.62 & 0.10 & 1
\end{tabular}

BMI: body mass index; IC: inspiratory capacity; MVV: maximal voluntary ventilation; and mMRC: modified Medical Research Council. 
in the evaluation of DM than does the BMI, a finding that suggests that, although the BMI is a good indicator of nutritional status, it does not reflect individual differences in body composition, such as abdominal fat distribution.

We found a relationship between MIP and DM that can be explained by the mechanical disadvantage in which the diaphragm is as a result of air trapping, which leads the inspiratory muscles to work in a shortened position, thus affecting their potential for contraction. ${ }^{(30)}$ Kodric et al. ${ }^{(40)}$ showed that inspiratory muscle training improved DM in patients with diaphragmatic dysfunction following cardiac surgery, a finding that suggests a relationship between improved MIP and DM.

Our results suggest that DM is a parameter that can provide information on respiratory mechanics in patients with COPD and that is related to certain pulmonary parameters $\left(\mathrm{FEV}_{1}, \mathrm{FEV}_{1} / \mathrm{FVC}, \mathrm{FVC}, \mathrm{IC}\right.$, and MVV) and functional parameters. However, studies involving a higher number of patients are needed in order to examine the relationship between DM and PADL.

One potential limitation of the present study is that no stage I COPD patients were evaluated. However, this is a common problem in the literature, given that stage I COPD patients are usually asymptomatic and, consequently, do not seek medical attention. Nevertheless, the results obtained in the present study cannot be extrapolated to all stages of COPD severity. In addition, the posture adopted during DM evaluation might influence the result obtained; therefore, we suggest that DM be evaluated in the orthostatic and supine positions in future studies.

In summary, in patients with COPD, DM is related to airway obstruction, lung hyperinflation, ventilatory capacity, and the perception of dyspnea. However, it appears to have no relationship with PADL.

\section{REFERENCES}

1. Iwasawa T, Kagei S, Gotoh T, Yoshiike Y, Matsushita K, Kurihara H, et al. Magnetic resonance analysis of abnormal diaphragmatic motion in patients with emphysema. Eur Respir J. 2002;19(2):225-31. https:// doi.org/10.1183/09031936.02.00044602

2. Paulin E, Yamaguti WP, Chammas MC, Shibao S, Stelmach R, Cukier $A$, et al. Influence of diaphragmatic mobility on exercise tolerance and dyspnea in patients with COPD. Respir Med. 2007;101(10): 2113-8. https://doi.org/10.1016/ן.rmed.2007.05.024

3. Dos Santos Yamaguti WP, Paulin E, Shibao S, Chammas MC, Salge JM, Ribeiro M, et al. Air trapping: The major factor limiting diaphragm mobility in chronic obstructive pulmonary disease patients. Respirology. 2008;13(1):138-44. https://doi.org/10.1111/j.1440 1843.2007.01194.x

4. Yamaguti WP, Claudino RC, Neto AP, Chammas MC, Gomes AC Salge JM, et al. Diaphragmatic breathing training program improves abdominal motion during natural breathing in patients with chronic obstructive pulmonary disease: a randomized controlled trial. Arch Physic Med Rehab. 2012;93(4):571-7. https://doi.org/10.1016/j. apmr.2011.11.026

5. Sociedade Brasileira de Pneumologia e Tisiologia. II Consenso Brasileiro sobre Doença Pulmonar Obstrutiva Crônica - DPOC - 2004 J Bras Pneumol. 2004;30(Suppl 5):S1-S42.

6. Watz H, Waschki B, Boehme C, Claussen M, Meyer T, Magnussen $\mathrm{H}$. Extrapulmonary effects of chronic obstructive pulmonary disease on physical activity: a cross-sectional study. Am J Respir Crit Care Med. 2008:177(7):743-51. https://doi.org/10.1164/rccm.20070710110C

7. Bossenbroek L, de Greef MH, Wempe JB, Krijnen WP, Ten Hacken $\mathrm{NH}$. Daily physical activity in patients with chronic obstructive pulmonary disease: a systematic review. COPD. 2011:8(4):306-19. https://doi.org/10.3109/15412555.2011.578601

8. Rabe KF, Hurd S, Anzueto A, Barnes PJ, Buist SA, Calverley P, et al Global strategy for the diagnosis, management, and prevention of chronic obstructive pulmonary disease: GOLD executive summary. Am J Respir Crit Care Med. 2007;176(6):532-55 https://doi org/10.1164/rccm.200703-456SO

9. Global Initiative for Chronic Obstructive Lung Disease [homepage on the Internet]. Bethesda: Global Initiative for Chronic Obstructive Lung Disease. [cited 2016 Jan 10]. Global strategy for the diagnosis, management, and prevention of COPD - 2015. Available from: http:// goldcopd.org/global-strategy-diagnosis-management-preventioncopd-2015/

10. Skumlien S, Hagelund T, Bjørtuft O, Ryg MS. A field test of functional status as performance of activities of daily living in COPD patients. Respir Med. 2006;100(2):316-23. https://doi.org/10.1016/j. rmed.2005.04.022

11. Davachi B, Lari SM, Attaran D, Tohidi M, Ghofraniha L, Amini M, et al. The relationship between diaphragmatic movements in sonographic assessment and disease severity in patients with stable

chronic obstructive pulmonary disease (COPD). J Cardiothorac Med. 2014;2(3):187-92

12. Yamaguti WP, Paulin E, Salge JM, Chammas MC, Cukier A, Carvalho CR. Diaphragmatic dysfunction and mortality in patients with COPD. J Bras Pneumol. 2009;35(12):1174-81. https://doi.org/10.1590/ S1806-37132009001200003

13. Scott S, Fuld JP, Carter R, McEntegart M, MacFarlane NG. Diaphragm ultrasonography as an alternative to whole-body plethysmography in pulmonary function testing. J Ultrasound Med. 2006;25(2):225-32.

14. Decramer M, Jiang TX, Demedts M. Effects of acute hyperinflation on chest wall mechanics in dogs. J Appl Physiol (1985). 1987:63(4):1493-8.

15. Sinderby C, Spahija J, Beck J, Kaminski D, Yan S, Comtois N, et al. Diaphragm activation during exercise in chronic obstructive pulmonary disease. Am J Respir Crit Care Med. 2001;163(7):163741. https://doi.org/10.1164/airccm.163.7.2007033

16. Miller MR, Hankinson J, Brusasco V, Burgos F, Casaburi R, Coates A et al. Standardisation of spirometry. Eur Respir J. 2005:26(2):319-38. https://doi.org/10.1183/09031936.05.00034805

17. Pereira CA, Sato T, Rodrigues SC. New reference values for forced spirometry in white adults in Brazil. J Bras Pneumol. 2007;33(4):397406. https://doi.org/10.1590/S1806-37132007000400008

18. Souza RB. Pressões respiratórias estáticas máximas. In: Sociedade Brasileira de Pneumologia e Tisiologia. Diretrizes para testes de função pulmonar. J Pneumol. 2002;28(Suppl 3):S155-S165.

19. Neder J, Andreoni S, Lerario M, Nery L. Reference values for lung function tests. II. Maximal respiratory pressures and voluntary ventilation. Braz J Med Biol Res. 1999;32(6):719-27. https://doi. org/10.1590/S0100-879X1999000600007

20. Leal BCE. Validade e confiabilidade da fluoroscopia por radiografia digital: uma nova forma de avaliar a mobilidade diafragmática [dissertation]. Florianópolis: Universidade do Estado de Santa Catarina; 2014

21. Saltiel RV, Grams ST, Pedrini A, Paulin E. High reliability of measure of diaphragmatic mobility by radiographic method in healthy individuals Braz J Phys Ther. 2013;17(2):128-36. https://doi.org/10.1590/S141335552012005000076

22. Hajiro $T$, Nishimura $K$, Tsukino $M$, Ikeda $A$, Koyama $H$, Izumi $T$. Analysis of clinical methods used to evaluate dyspnea in patients with chronic obstructive pulmonary disease. Am J Respir Crit Care Med 1998;158(4):1185-9. https://doi.org/10.1164/ajrccm.158.4.9802091

23. Pitta F, Troosters T, Spruit MA, Probst VS, Decramer M, Gosselink R. Characteristics of physical activities in daily life in chronic obstructive pulmonary disease. Am J Respir Crit Care Med. 2005;171(9):972-7. https://doi.org/10.1164/rccm.200407-8550C

24. Dancey C, Reidy J. Estatística sem matemática para psicologia: usando SPSS para Windows. 5th ed. Porto Alegre: Artmed; 2006.

25. World Health Organization. Obesity: preventing and managing the 
global epidemic. Report of a World Health Organization Consultation. Geneva: World Health Organization; 2000. p. 284-56.

26. De Troyer A. Effect of hyperinflation on the diaphragm. Eur Respir J. 1997;10(3):708-13.

27. Poole DC, Sexton WL, Farkas GA, Powers SK, Reid MB. Diaphragm structure and function in health and disease. Med Sci Sports Exerc. 1997;29(6):738-54. https://doi.org/10.1097/00005768-19970600000003

28. McKenzie DK, Butler JE, Gandevia SC. Respiratory muscle function and activation in chronic obstructive pulmonary disease. J Appl Physiol (1985). 2009;107(2):621-9. https://doi.org/10.1152/ japplphysiol.00163.2009

29. Unal O, Arslan H, Uzun K, Ozbay B, Sakarya ME. Evaluation of diaphragmatic movement with MR fluoroscopy in chronic obstructive pulmonary disease. Clin Imaging. 2000;24(6):347-50. https://doi. org/10.1016/S0899-7071(00)00245-X

30. Reid WD, Samrai B. Respiratory muscle training for patients with chronic obstructive pulmonary disease. Phys Ther. 1995;75(11):9961005.

31. Kang HW, Kim TO, Lee BR, Yu JY, Chi SY, Ban HJ, et al. Influence of diaphragmatic mobility on hypercapnia in patients with chronic obstructive pulmonary disease. J Korean Med Sci. 2011;26(9):120913. https://doi.org/10.3346/jkms.2011.26.9.1209

32. Freitas CG, Pereira CA, Viegas CA. Inspiratory capacity, exercise limitation, markers of severity, and prognostic factors in chronic obstructive pulmonary disease. J Bras Pneumol. 2007;33(4):389-96. https://doi.org/10.1590/S1806-37132007000400007

33. Iwasawa T, Takahashi H, Ogura T, Asakura A, Gotoh T, Shibata $H$, et al. Influence of the distribution of emphysema on diaphragmatic motion in patients with chronic obstructive pulmonary disease. Jpn J Radiol. 2011;29(4):256-64. https://doi.org/10.1007/s11604-010-05528

34. McConnell AK, Romer LM. Dyspnoea in health and obstructive pulmonary disease: the role of respiratory muscle function and training. Sports Med. 2004;34(2):117-32. https://doi. org/10.2165/00007256-200434020-00005

35. Park SK, Meldrum CA, Larson JL. Subgroup analysis of symptoms and their effect on functioning, exercise capacity, and physical activity in patients with severe chronic obstructive pulmonary disease. Heart Lung. 2013;42(6):465-72. https://doi.org/10.1016/j. hrtlng.2013.08.008

36. Esteban C, Quintana JM, Aburto M, Moraza J, Egurrola M, PérezIzquierdo J, et al. Impact of changes in physical activity on healthrelated quality of life among patients with COPD. Eur Respir $\mathrm{J}$. 2010;36(2):292-300. https://doi.org/10.1183/09031936.00021409

37. Hernandes NA, Teixeira Dde C, Probst VS, Brunetto AF, Ramos EM, Pitta F. Profile of the level of physical activity in the daily lives of patients with COPD in Brazil. J Bras Pneumol. 2009;35(10):949-56.

38. Brandes M, Rosenbaum D. Correlations between the step activity monitor and the DynaPort ADL-monitor. Clin Biomech (Bristol, Avon). 2004;19(1):91-4. https://doi.org/10.1016/j.clinbiomech.2003.08.001

39. Kantarci F, Mihmanli I, Demirel MK, Harmanci K, Akman C, Aydogan $F$, et al. Normal diaphragmatic motion and the effects of body composition: determination with M-mode sonography. J Ultrasound Med. 2004;23(2):255-60.

40. Kodric M, Trevisan R, Torregiani C, Cifaldi R, Longo C, Cantarutti F, et al. Inspiratory muscle training for diaphragm dysfunction after cardiac surgery. J Thorac Cardiovasc Surg. 2013;145(3):819-23. https://doi. org/10.1016/j.jtcvs.2012.07.087 